\title{
Case Report Watershed Infarct in Beta-Thalassemia Major Patient
}

\author{
Behnaz Ansari, ${ }^{1,2}$ Mohammad Saadatnia, ${ }^{1,2}$ and Ali Asghar Okhovat ${ }^{2,3}$ \\ ${ }^{1}$ Isfahan Neurosciences Research Center, Alzahra Research Institute, Isfahan University of Medical Sciences, Isfahan, Iran \\ ${ }^{2}$ Department of Neurology, Isfahan University of Medical Sciences, Isfahan, Iran \\ ${ }^{3}$ Department of Neurology, Tehran University of Medical Sciences, Sina Hospital, Tehran, Iran
}

Correspondence should be addressed to Behnaz Ansari; ansaribehnaz@yahoo.com

Received 11 August 2016; Revised 17 November 2016; Accepted 7 February 2017; Published 27 March 2017

Academic Editor: Dennis J. Rivet

Copyright (C) 2017 Behnaz Ansari et al. This is an open access article distributed under the Creative Commons Attribution License, which permits unrestricted use, distribution, and reproduction in any medium, provided the original work is properly cited.

Background. The mechanism of stroke in beta-thalassemia was reported previously as cardioembolic and hypercoagulable state. However, there is no report of watershed infarct in beta-thalassemia anemia. Method. We present an adult $\beta$-thalassemia major patient with manifest asymptomatic chronic left carotid occlusion who suffered watershed infarct. Result. In the presence of asymptomatic chronic left internal carotid occlusion, we assumed that severe anemia (hemoglobin $=3$ ) at admission leads to watershed infarct. Conclusion. Watershed infarct seems to be the cause of stroke in cases of $\beta$-thalassemia major with severe anemia. Blood transfusion can be applied in the setting of acute brain ischemia in such high risk patients.

\section{Introduction}

Thalassemia consists of inherited defects in the rate of synthesis of one or more of the globin chains of hemoglobin [1]. Beta-thalassemia is a condition of impaired production of beta globin chains, leading to relative excess of alpha globin chains [2]. Anemia, hemolysis, and ineffective erythropoiesis form the pathology for clinical presentations of beta-thalassemia [3-6]. Acute neurological complications in patients with beta-thalassemia have been reported such as cerebral ischemia, spinal cord fractures, and compression from extramedullary hematopoietic tumors [7-9].

Logothetis et al. reviewing 138 cases of beta-thalassemia major (B-TM) in Greece and described a stroke syndrome in 2 patients and transient ischemic attack in about $20 \%$ of the cases [10]. In Italian multicenter study of 735 patients with B-TM reported 16 thromboembolic events with presentation of headache, seizure, and hemiparesis [11]. In patients with $\mathrm{B}$ thalassemia/hemoglobin $\mathrm{E}$ disease and alpha thalassemia, cerebral thrombosis was detected [12, 13]. However, all these reports were from patients who were not given regular transfusions. The mechanism of stroke in beta-thalassemia was reported previously as hypercoagulable state and cardioembolic and large vessels thrombosis [14, 15]. However, watershed infarct in beta-thalassemia anemia has been rarely reported before.

We report a case of beta-thalassemia major with severe anemia that was not given regular transfusion and presented with stroke.

\section{Case Report}

In Nov 2014, a 25-year-old woman with past history of betathalassemia major was admitted to the hospital with right hemiparesis. She was a known case of beta-thalassemia major with regular blood transfusion until 9 years old. The mean hemoglobin of patient was $9 \mathrm{gr} / \mathrm{dl}$. But she had twice hemolysis after transfusion, and after this situation, she refused to receive blood transfusion. She did not take any drug after this side effect. She had past history of gallbladder stone one month before the current hemiparesis and had undergone cholecystectomy. In this stage the mean $\mathrm{Hb}$ was $7 \mathrm{gr} / \mathrm{dl}$, so before the surgery she received blood transfusion. In this admission, on general examination, she was undernourished with a short stature. Head and neck examination revealed depressed cranial vault, frontal bossing, retracted upper lip, and saddle nose (severe face deformity due to extramedullary 


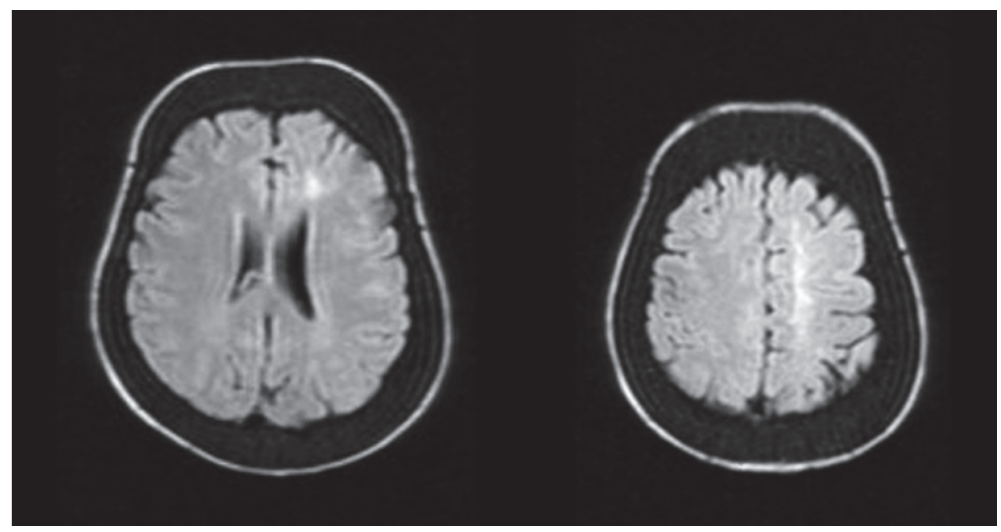

FIGURE 1: Magnetic resonance imaging in patient with thalassemia major showed flair signal intensity abnormalities in left watershed area and diploe space expansion.

hematopoiesis). On neurological examination, she was right hemiparesis (force: 3/5); her cranial nerves and sensory function were intact. In paraclinic tests, $\mathrm{Hb}$ was $3.4 \mathrm{gr} / \mathrm{dl}$ and echocardiography showed increased aortic flow. Abdominal sonography revealed hepatosplenomegaly. Brain MRI showed hypersignal intensity in left cortical watershed area (Figure 1). Brain MRA and CT angiography showed chronic total occlusion of left internal carotid artery at from C2 till C5 segment (Figure 2). In transcranial duplex study of cervical and cerebral vessels, internalization of left external carotid artery, reverse flow of left anterior cerebral artery, and high peak systolic velocities (PSV $>125 \mathrm{~cm} / \mathrm{s}$ ) in all transcranial vessels were shown. After blood transfusion without any thrombotic or anticoagulant drugs, hemiparesis was improved in three days.

Due to severe anemia after 3 months, she had undergone splenectomy and anemia was improved. Before surgery the mean $\mathrm{Hb}$ was $6 \mathrm{gr} / \mathrm{dl}$ and after that the mean $\mathrm{Hb}$ increased to $9 \mathrm{gr} / \mathrm{dl}$ and serum ferritin was $1500 \mathrm{mg} / \mathrm{l}$. After 6 months of follow-up, modified Rankin scale was zero and transcranial duplex showed normal PSV.

\section{Discussion}

Watershed infarct is defined as an ischemic or blood flow blockage that is localized to the border zones [16]. Watershed strokes are localized to two primary regions of the brain and termed cortical watersheds (CWS) and internal watersheds (IWS) [17].

The causes of watershed infarct contain congestive heart failure, angiopathy, hypotension, hypertension, hyperlipidemia, carotid artery stenosis, and diseases such as sickle cell anemia [18-20].

Thalassemia is congenital hemolytic disorder caused by a partial or complete deficiency of alpha or beta globin chain synthesis. Ischemic strokes have been reported in $0.25 \%$ of patients with beta-thalassemia major [21].

In an Iranian study, stroke was documented in $0.46 \%$ of patients with beta-thalassemia major [22].

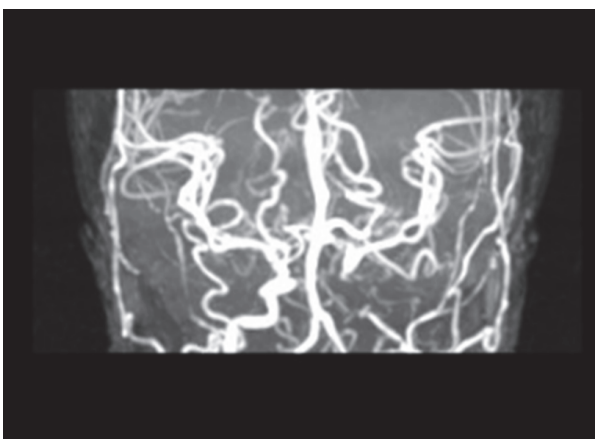

FIGURE 2: Magnetic resonance arteriography in patient with thalassemia major showed complete occlusion of left internal carotid and diffuse vasospasm.

The presence of persistent hypercoagulable state combined with the infrequent thrombotic events suggests that thrombosis is largely a subclinical process in thalassemia [23, 24]. These thrombi could contribute to the pulmonary hypertension [25-30] and high frequency of ischemic brain lesions associated with asymptomatic (silent stroke) and symptomatic brain damage as detected by MRI [31]. Carotid artery intima media thickness (CIMT) shows a strong relationship with features of iron overload and atherosclerotic changes in beta-thalassemia major patients; however use of Doppler measurement of CIMT is recommend in beta-thalassemia major patients as a noninvasive diagnostic method to predict early atherosclerotic changes as well as in the follow-up to prevent progression of atherosclerosis [32].

Several etiologic factors play a role in hypercoagulable state in thalassemia [32-35].

The beneficial role of regular transfusions is illustrated by observation that thromboembolic accident is more frequently recorded with limited transfusion. Normal red blood cells (RBCs) can eliminate the abnormal aggregation observed with thalassemic RBCs [36].

In addition to asymptomatic and symptomatic stroke due to hypercoagulable state, cardioembolic and large vessels 
thrombosis also were reported as the cause of stroke in thalassemia [14, 15, 37, 38].

The relationship of iron overload effect on brain ischemia and infarction in beta-thalassemia major was evaluated in some articles and in southern Iran a higher frequency (66\%) was reported for silent cerebral infarctions in transfusiondependent patients with beta-thalassemia major [38]. But our case refused to receive transfusion due to hemolysis, so this theory was not accepted for this patient and on the other hand our patient has severe anemia and, after transfusion, hemiparesis was improved.

However, watershed infarct is rare type. The mechanism of watershed infarct in this patient is coexistence of chronic left internal carotid occlusion (ICA) and severe anemia. It seems left ICA occlusion alone, due to efficient collateral flow, could not lead to infarct; however superimposition of severe anemia leads to watershed infarct in the same side of ICA occlusion.

The etiology of ICA occlusion in this patient could be due to extramedullary hematopoiesis in sellar region, sphenoid bone, and petrous bone.

In conclusion, watershed infarct seems to be the cause of stroke in $\beta$-thalassemia major with severe anemia. Blood transfusion can be applied in the setting of acute brain ischemia in such high risk patients.

\section{Competing Interests}

The authors declare that they have no competing interests.

\section{References}

[1] D. Rund and E. Rachmilewitz, "Pathophysiology of $\alpha$ - and $\beta$ thalassemia: therapeutic implications," Seminars in Hematology, vol. 38, no. 4, pp. 343-349, 2001.

[2] B. G. Forget, "The pathophysiology and molecular genetics of beta thalassemia," Mount Sinai Journal of Medicine, vol. 60, no. 2, pp. 95-103, 1993.

[3] M. Goerner, S. Gerull, E. Schaefer, M. Just, M. Sure, and P. Hirnle, "Painful spinal cord compression as a complication of extramedullary hematopoiesis associated with $\beta$-thalassemia intermedia," Strahlentherapie und Onkologie, vol. 184, no. 4, pp. 224-226, 2008.

[4] S. A. Salehi, T. Koski, and S. L. Ondra, "Spinal cord compression in beta-thalassemia: case report and review of the literature," Spinal Cord, vol. 42, no. 2, pp. 117-123, 2004.

[5] B. Aliberti, A. Patrikiou, A. Terentiou, S. Frangatou, and A. Papadimitriou, "Spinal cord compression due to extramedullary haematopoiesis in two patients with thalassaemia: complete regression with blood transfusion therapy," Journal of Neurology, vol. 248, no. 1, pp. 18-22, 2001.

[6] M. A. Martinez-Rodrigo, L. Sanjuanbenito, E. Rodriguez del Barrio, J. Martinez-San Millan, and D. Saldana, "Spinal cord compression secondary to epidural extramedullary hematopoiesis in thalassemia: a clinical case and review of literature," Revista de Neurologia, vol. 27, no. 160, pp. 998-1004, 1998.

[7] D. Sinniah, V. Vignaendra, and K. Ahmad, "Neurological complications of beta-thalassaemia major," Archives of Disease in Childhood, vol. 52, no. 12, pp. 977-979, 1977.
[8] G. Massenkeil, W. Wichmann, F. Krummenacher, and K. Rhyner, "Reversible rückenmarkskompression durch extramedulläre blutbildungsherde bei thalassämie," Deutsche Medizinische Wochenschrift, vol. 118, no. 4, pp. 100-106, 1993.

[9] B. Aarabi, M. Haghshenas, and V. Rakeii, "Visual failure caused by suprasellar extramedullary hematopoiesis in beta thalassemia: case report," Neurosurgery, vol. 42, no. 4, pp. 922-926, 1998.

[10] J. Logothetis, M. Constantoulakis, J. Economidou et al., “Thalassemia major (homozygous beta-thalassemia). A survey of 138 cases with emphasis on neurologic and muscular aspects," Neurology, vol. 22, no. 3, pp. 294-304, 1972.

[11] C. Borgna Pignatti, V. Carnelli, V. Caruso et al., "Thromboembolic events in beta thalassemia major: an Italian multicenter study," Acta Haematologica, vol. 99, no. 2, pp. 76-79, 1998.

[12] V. Wong, Y. L. Yu, R. Liang, W. K. Tso, A. M. C. Li, and T. K. Chan, "Cerebral thrombosis in $\beta$-thalassemia/hemoglobin $\mathrm{E}$ disease," Stroke, vol. 21, no. 5, pp. 812-816, 1990.

[13] S. C. Tso, T. K. Chan, and D. Todd, "Venous thrombosis in haemoglobin $\mathrm{H}$ disease after splenectomy," Australian and New Zealand Journal of Medicine, vol. 12, no. 6, pp. 635-638, 1982.

[14] K. M. Musallam, A. T. Taher, M. Karimi, and E. A. Rachmilewitz, "Cerebral infarction in $\beta$-thalassemia intermedia: breaking the silence," Thrombosis Research, vol. 130, no. 5, pp. 695-702, 2012.

[15] S. Haghpanah and M. Karimi, "Cerebral thrombosis in patients with $\beta$-thalassemia: a systematic review," Blood Coagulation and Fibrinolysis, vol. 23, no. 3, pp. 212-217, 2012.

[16] A. ToRvik, "The pathogenesis of watershed infarcts in the brain," Stroke, vol. 15, no. 2, pp. 221-223, 1984.

[17] I. Momjian-Mayor and J.-C. Baron, "The pathophysiology of watershed infarction in internal carotid artery disease: review of cerebral perfusion studies," Stroke, vol. 36, no. 3, pp. 567-577, 2005.

[18] J. Miklossy, "Cerebral hypoperfusion induces cortical watershed microinfarcts which may further aggravate cognitive decline in Alzheimer's disease," Neurological Research, vol. 25, no. 6, pp. 605-610, 2003.

[19] G. A. Donnan, M. Fisher, M. Macleod, and S. M. Davis, "Stroke," The Lancet, vol. 371, no. 9624, pp. 1612-1623, 2008.

[20] L. A. Verduzco and D. G. Nathan, "Sickle cell disease and stroke," Blood, vol. 114, no. 25, pp. 5117-5125, 2009.

[21] A. Taher, H. Isma'eel, G. Mehio et al., "Prevalence of thromboembolic events among 8,860 patients with thalassaemia major and intermedia in the Mediterranean area and Iran," Thrombosis and Haemostasis, vol. 96, no. 4, pp. 488-491, 2006.

[22] M. Karimi, M. Khanlari, and E. A. Rachmilewitz, "Cerebrovascular accident in $\beta$-thalassemia major $(\beta$-TM) and $\beta$ thalassemia intermedia ( $\beta$-TI)," American Journal of Hematology, vol. 83, no. 1, pp. 77-79, 2008.

[23] D. Sonakul, P. Pacharee, T. Laohapand, S. Fucharoen, and P. Wasi, "Pulmonary artery obstruction in thalassemia," The Southeast Asian Journal of Tropical Medicine and Public Health, vol. 11, pp. 516-523, 1980.

[24] A. Sumiyoshi, K. Thakerngpol, and D. Sonakul, "Pulmonary microthromboemboli in thalassemic cases," The Southeast Asian Journal of Tropical Medicine and Public Health, vol. 23, pp. 29-31, 1992.

[25] D. Grisaru, E. A. Rachmilewitz, M. Mosseri et al., "Cardiopulmonary assessment in beta-thalassemia major," Chest, vol. 98, no. 5, pp. 1138-1142, 1990. 
[26] D. K. Luyt, G. A. Richards, H. Roode, R. J. Dowdeswell, A. J. van Rensburg, and S. G. Reinach, "Thalassemia: lung function with reference to iron studies and reactive oxidant status," Pediatric Hematology and Oncology, vol. 10, no. 1, pp. 13-23, 1993.

[27] G. P. Grant, A. L. Mansell, J. H. Graziano, and R. B. Mellins, “The effect of transfusion on lung capacity, diffusing capacity, and arterial oxygen saturation in patients with thalassemia major," Pediatric Research, vol. 20, no. 1, pp. 20-23, 1986.

[28] A. Koren, I. Garty, D. Antonelli, and E. Katzuni, "Right ventricular cardiac dysfunction in beta-thalassemia major," The American Journal of Diseases of Children, vol. 141, pp. 93-96, 1987.

[29] Z.-D. Du, N. Roguin, E. Milgram, K. Saab, and A. Koren, "Pulmonary hypertension in patients with thalassemia major," American Heart Journal, vol. 134, no. 3, pp. 532-537, 1997.

[30] P. Chotivittayatarakorn, P. Seksarn, C. Pathmanand, C. Thisyakorn, and V. Sueblinvong, "Cardiac dysfunction in beta-thalassemic children," Journal of the Medical Association of Thailand, vol. 76, no. 11, pp. 591-596, 1993.

[31] L. Manfrè, E. Giarratano, A. Maggio, A. Banco, G. Vaccaro, and R. Lagalla, "MR imaging of the brain: findings in asymptomatic patients with thalassemia intermedia and sickle cellthalassemia disease," American Journal of Roentgenology, vol. 173, no. 6, pp. 1477-1480, 1999.

[32] H. A. Abdelsamei, A. M. El-Sherif, A. M. Ismail, and G. L. Abdel Hakeem, "The role of the carotid doppler examination in the evaluation of atherosclerotic changes in $\beta$-thalassemia patients," Mediterranean Journal of Hematology and Infectious Diseases, vol. 7, no. 1, Article ID e2015023, 2015.

[33] H. Hassoun, Y. Wang, J. Vassiliadis et al., "Targeted inactivation of murine band 3 (AE1) gene produces a hypercoagulable state causing widespread thrombosis in vivo," Blood, vol. 92, no. 5, pp. 1785-1792, 1998.

[34] T. M. Kaysser, N. J. Wandersee, R. T. Bronson, and J. E. Barker, "Thrombosis and secondary hemochromatosis play major roles in the pathogenesis of jaundiced and spherocytic mice, murine models for hereditary spherocytosis," Blood, vol. 90, no. 11, pp. 4610-4619, 1997.

[35] N. J. Wandersee, J. C. Lee, S. A. Deveau, and J. E. Barker, "Reduced incidence of thrombosis in mice with hereditary spherocytosis following neonatal treatment with normal hematopoietic cells," Blood, vol. 97, no. 12, pp. 3972-3975, 2001.

[36] S. Chen, A. Eldor, G. Barshtein et al., "Enhanced aggregability of red blood cells of $\beta$-thalassemia major patients," American Journal of Physiology-Heart and Circulatory Physiology, vol. 39, no. 6, pp. H1951-H1956, 1996.

[37] S. Vassilopoulou, E. Anagnostou, G. Paraskevas, and K. Spengos, "Etiology and treatment of ischaemic stroke in patients with $\beta$-thalassemia major," European Journal of Neurology, vol. 18, no. 12, pp. 1426-1428, 2011.

[38] M. Karimi, F. Toosi, S. Haghpanah, P. Pishdad, A. Avazpour, and E. A. Rachmilewitz, "The frequency of silent cerebral ischemia in patients with transfusion-dependent $\beta$-thalassemia major," Annals of Hematology, vol. 95, no. 1, pp. 135-139, 2016. 


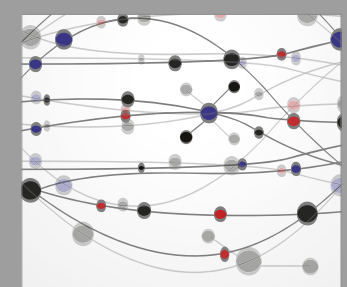

The Scientific World Journal
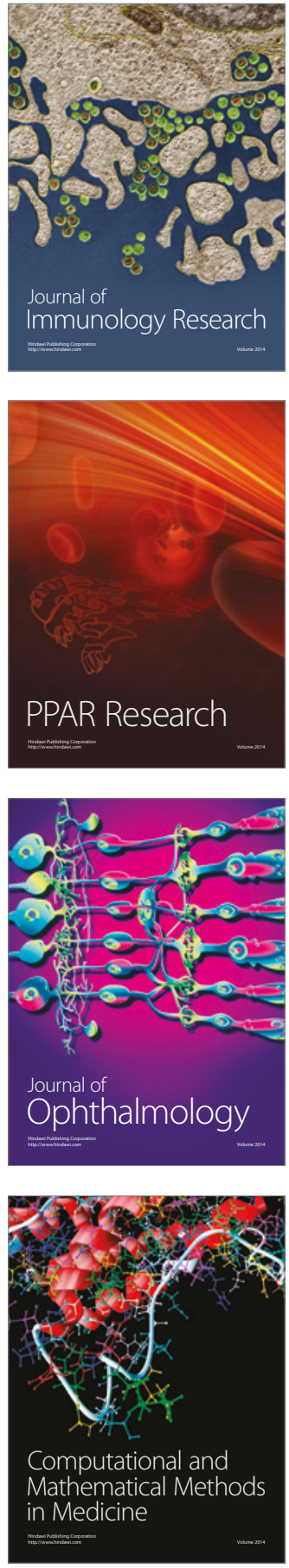

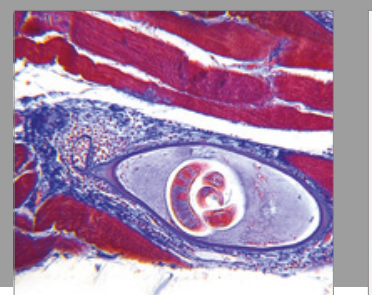

Gastroenterology Research and Practice
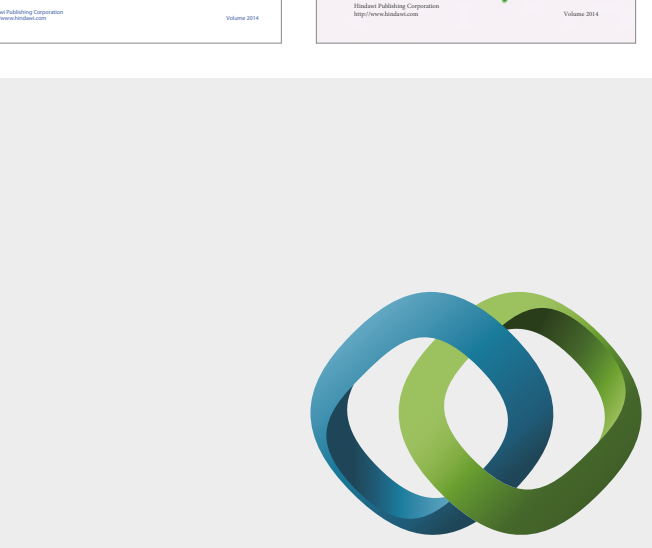

\section{Hindawi}

Submit your manuscripts at

https://www.hindawi.com
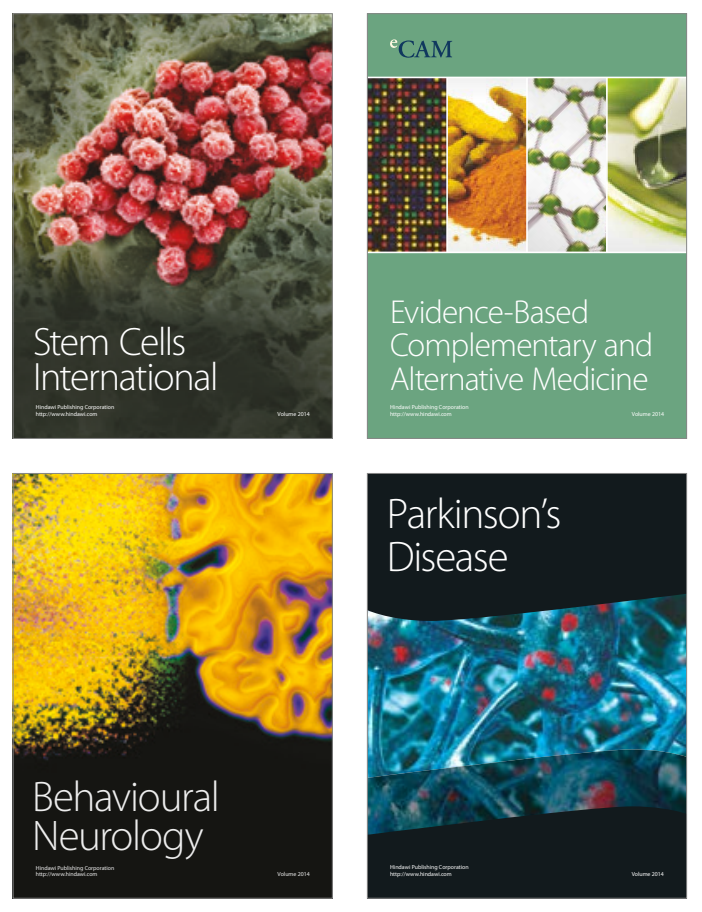


Disease Markers
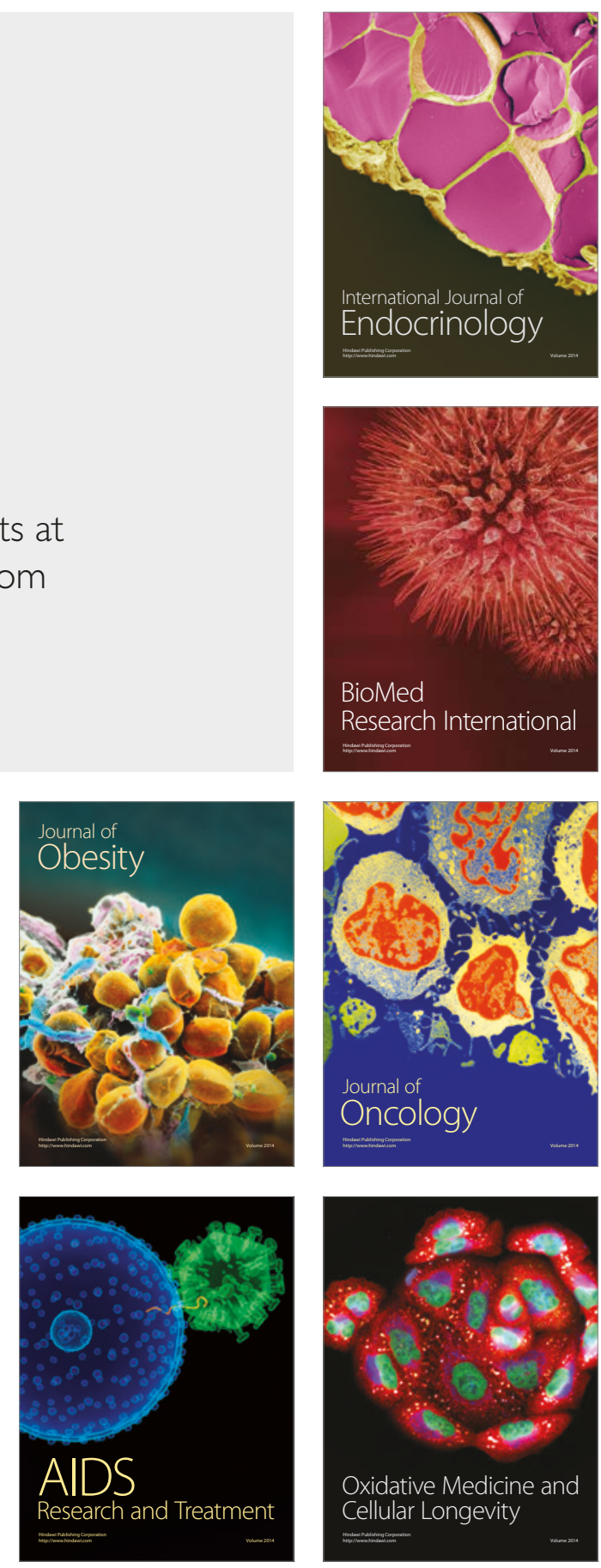